\title{
Early versus delayed laparoscopic cholecystectomy in treatment of acute cholecystitis
}

\author{
Rajcok $\mathrm{M}^{1}$, Bak V${ }^{1}$, Danihel L², Kukucka $\mathbf{M}^{1}$, Schnorrer $\mathbf{M}^{1}$ \\ Surgical Clinic of University Hospital Bratislava, Slovakia. matus.rajcok@gmail.com
}

\begin{abstract}
BACKGROUND: Acute cholecystitis is one of the most frequent diseases occurring in the developed countries of the world. Since the advent of laparoscopic cholecystectomy there has been a lack of agreement regarding the timing of the operation in the treatment of acute cholecystitis.

METHODS: From September 2012 to January 2015 we carried out a prospective randomized trial at the IIIrd Surgical Department of University Hospital Milosrdní bratia in Bratislava. The aim of the trial was to compare the two basic approaches of the treatment of acute cholecystitis. During our trial, 62 patients with acute cholecystitis were admitted to the surgery department and 31 patients were treated with an early laparoscopic cholecystectomy within 72 hours after the appearance of the symptoms. Other 31 patients were primarily treated with antibiotics and subsequently underwent a delayed cholecystectomy after 6-8 weeks.

RESULTS: Our results suggest several advantages of the early laparoscopic cholecystectomy such as shorter operation time, lower conversion rate, shorter length of hospital stay, shorter postoperative convalescence and lower cost of hospitalization.

CONCLUSION: According to these results we believe that immediate laparoscopic cholecystectomy (within 24 hours from the patient's admission to hospital) should become a preferred method of treatment of the patients with acute cholecystitis (Tab. 1, Fig. 2, Ref. 17). Text in PDF www.elis.sk.

KEY WORDS: acute cholecystitis, early laparoscopic cholecystectomy, delayed laparoscopic cholecystectomy, prospective randomized trial.
\end{abstract}

\section{Introduction}

There are still ongoing debates concerning the timing of the operation for acute cholecystitis. An early cholecystectomy is an operation performed within 72 hours since the appearance of the symptoms. In recent studies, the so-called immediate laparoscopic cholecystectomy is being mentioned, defined as cholecystectomy carried out within 24 hours since the patient's admission to the hospital (10). A delayed cholecystectomy is an operation performed at least $6-8$ weeks after the subsidence of the symptoms of acute cholecystitis (1).

\section{Material and methods}

Between September 2012 and January 2015 we carried out a prospective randomized trial including patients with acute cholecystitis treated at IIIrd surgical department. The inclusion criteria for our study were the duration of abdominal pain in the right upper quadrant shorter than 72 hours, positive Murphy's sign, eleva-

${ }^{1}$ Surgical Clinic of University Hospital Bratislava, Slovakia, ${ }^{2}$ Institute of Pathological Anatomy, Faculty of Medicine, Comenius university, Bratislava

Address for correspondence: M. Rajcok, Surgical Clinic of University Hospital Bratislava, Slovakia, Legerskeho 14, SK-831 02 Bratislava, Slovakia. tion of inflammatory parameters (leukocytes above $10 \times 10^{3} / \mathrm{l}$ ) and ultrasonographic (USG) findings of acute cholecystitis.

The patients included in our trial were divided into two groups. The first group consisted of patients who underwent the operation within 72 hours since the occurrence of first symptoms. The second group included patients treated conservatively with infusions and antibiotic (ATB) therapy. These patients were subsequently scheduled for an elective laparoscopic cholecystectomy within 6-8 weeks after acute cholecystitis. During this period, a part of the patients demonstrated a repeating occurrence of acute cholecystitis symptoms. These patients were re-hospitalized and underwent an acute operation.

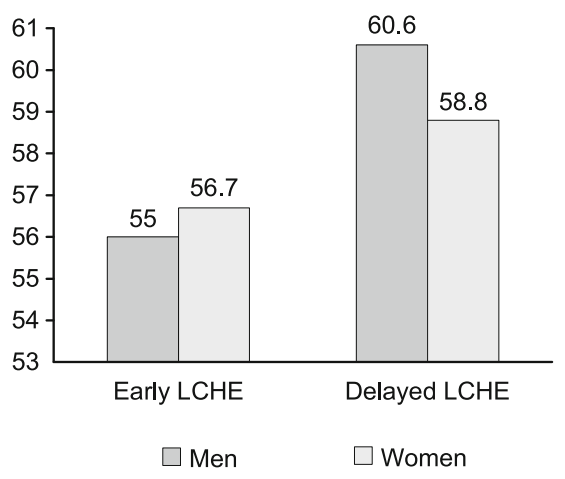

Fig. 1. Average age of patients in both observed groups. 
The study group consisted of 62 patients diagnosed with acute cholecystitis, 29 women and 33 men. The average age of the patients was 57.8 years. The average duration of symptoms in both subgroups was 2.5 days. The average leukocyte count by the time of admission to the clinic was $13.36 \times 10^{3} / 1$. All the patients were empirically prescribed ATB therapy with fluoroquinolone (Ciprofloxacin). Laparoscopic approach was used in all 62 patients. However, in 7 cases, the operation was converted to laparotomy due to perioperative finding of severe adhesions.

\section{Results}

In the period from September 2012 to January 2015 we included 62 patients diagnosed with acute cholecystitis into our study group.

The first group consisted of patients treated with an early LCHE. This group consisted of 31 patients, 15 women and 16 men. The average age was 56 years (men) and 56.7 years (women) (Fig. 1 ). The average initial value of leukocytes by the time of admission was $12.75 \times 10^{3} / \mathrm{l}$. In 18 cases, the USG examination described thickening of the cholecystic wall up to $10 \mathrm{~mm}$ with pericholecystic edema. In 11 cases gallbladder hydrops was also present. In 2 cases the USG described a covered gallbladder perforation.

In 20 patients, we performed the operation within 24 hours since the admission to our department. In 11 cases the operation was carried out within 48 hours. In 30 cases the perioperative findings included edematous and thickened gallbladder wall and emerging adhesions, without signs of perforation. In these patients we performed a LCHE with an average duration of 75.9 minutes. In one patient, we discovered a covered perforation of the gallbladder with a pericholecystic abscess. In this case we converted LCHE to a laparotomic anterograde cholecystectomy.

Complications observed in the first group included one case of hematoma in the gallbladder bed and two cases of seroma in the supraumbilical wound. In both cases the condition was successfully treated with ATB therapy. Histological examinations verified 21 cases of acute and 10 cases of subacute cholecystitis. The average duration of hospitalization in the first group was 7.4 days and the conversion rate in this group was $3.2 \%$ (Fig. 2).
The second group included patients primarily treated with antibiotics followed by subsequent delayed LCHE after 6-8 weeks. This group consisted of 31 patients, 14 women and 17 men. The average age was 60.6 years (men) and 58.8 years (women) (Fig. 1 ). The average age of patients in this group was 59.8 years. The average leukocyte count by the time of admission was $13.84 \times 10^{3}$. In 26 patients, the USG examination verified gallbladder wall thickening up to $10 \mathrm{~mm}$ and in 4 patients, it discovered hydrops of the gallbladder. In one case, the USG described a covered cholecystic perforation.

During the first hospitalization, these patients were treated with antibiotics and infusion therapy. After an improvement in their clinical condition, USG findings and decrease of inflammatory parameters they were released into home care. The average length of hospitalization was 5.7 days. The delayed cholecystectomy for these patients had been scheduled 6-8 weeks after the discharge.

However, five patients from the second group were re-hospitalized due to recurrence of acute cholecystitis and required acute cholecystectomy. Due to severe perioperative findings, the initial laparoscopic surgery was converted into laparotomic approach in three patients. The average time between the discharge and second admission was 14.2 days.

The remaining 26 patients underwent elective LCHE as planned, 6-8 weeks after acute cholecystitis. In 25 patients, the perioperative findings included a thickened fibrotic gallbladder wall with adhesions. In 23 cases, we were able to complete the operation laparoscopically. However, in 3 patients, we converted the operation due to severe perioperative findings. In general, the operation was more complicated in this group with increased average duration of the operation up to 90 minutes.

Early complications observed in the second group included two cases of increased secernation into the Redon drain. These patients were re-operated and in both cases we were able to stop the bleeding with laparotomy.. Other early complications included five cases of hematoma or seroma in the wound and one case of subhepatal hematoma. Histological examinations verified chronic cholecystitis in 26 cases and acute cholecystitis in 5 re-hospitalized patients. The length of both hospitalizations in the second group was 11.5 days. The conversion rate in this group was $16.1 \%$ (Fig. 2).
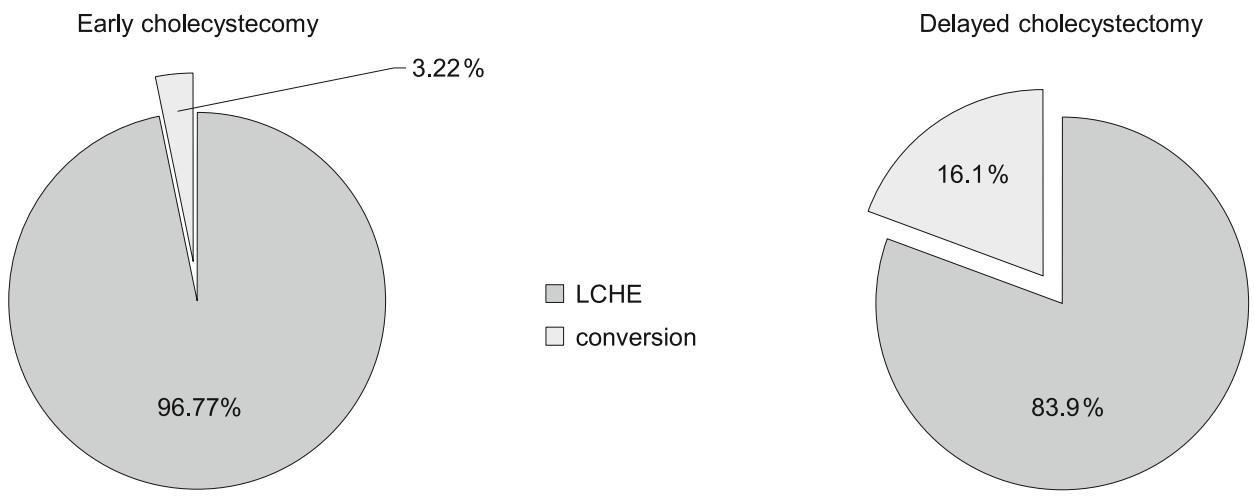

Fig. 2. Compared conversion rates in both observed samples. 
Tab. 1. Comparison of observed parameters in both samples.

\begin{tabular}{lccc}
\hline Group & Operation duration & Conversion rate & Early complications \\
\hline Early LCHE & 75.9 minutes & $3.2 \%$ & $12.9 \%$ \\
Delayed LCHE & 90.0 minutes & $16.1 \%$ & $32.3 \%$ \\
\hline
\end{tabular}

\section{Discussion}

Regarding the continuously rising incidence of acute cholecysticis in the developed countries of the world it is necessary to achieve a unified algorithm for its treatment. Nowadays, LCHE is considered a golden standard for acute cholecystitis treatment. However, there is still a certain lack of consensus regarding the timing of the operation. There are two basic approaches for acute cholecystitis treatment. The first one is a primary surgical approach - early cholecystectomy. The second approach is a primary conservative antibiotic treatment followed by a delayed cholecystectomy after a period of 6-8 weeks.

At the beginning of the era of laparoscopic surgery, acute cholecystitis was considered a relative contraindication of an early LCHE. This opinion originated in a concern of potentially damaging the bile ducts in a disarranged inflammatory background. These concerns were fueled by a significant number of conversions. These were the reasons for choosing conservative therapy more frequently and for cholecystectomy being delayed after subsiding of the inflammation. As the experience in the area of laparoscopic operations increased, the amount if iatrogenic damage to the bile ducts decreased, and so did the amount of conversions. This fact initiated the discussion concerning the correct timing of early laparoscopic cholecystectomy in the treatment of acute cholecystitis. Moreover, there is no unified opinion on the definition of early cholecystectomy. While one group of authors defines early cholecystectomy as an operation carried out within 24 hours, others define it as an operation within 72 hours. The question whether this timeframe should be counted because of the symptoms occurrence or because the patient's admission to the hospital has not been resolved yet.

Several studies worldwide have focused on the optimal timing of the operation. Based on the DVGA directive (Deutche Gesselschaft fur Allgemein und Viszeralchirurgie), acute cholecystitis is an indication for an early LCHE in a timeframe within 72 hours because of the diagnosis of inflammation. An exception can be made in patients with higher operation risk or patients with diagnosis prolonged by $1-5$ days. In this group of patients, a conservative treatment is recommended, followed by a delayed cholecystectomy after 6 weeks (5). The EAES directive (European Association for Endoscopic Surgery) recommends a surgical intervention, although it does not specify the timing of the operation. According to this study, there are no differences in the success rate of early and delayed cholecystectomy (6). The SAGES directive (Society of American Gastrointestinal Endoscopic Surgeons) does not indicate an increased amount of conversions or complications in delayed cholecystectomies. However, it does admit possible advantages in early LCHE, such as reduction of hospitalizationrelated medical expenses in patients operated early (7). The To- kyo directive describes different approaches regarding the degree of acute cholecystitis. It recommends early cholecystectomy in a case of mild or medium cholecystitis and percutaneous drainage of the gallbladder with a subsequent delayed cholecystectomy in a case of severe cholecystitis $(8,12)$.

The management of treatment depends on the department the patient was initially admitted to. Patients admitted to internal departments are primarily treated conservatively. In patients admitted to surgical clinics, early LCHE is being considered nowadays. Despite these opinions, early LCHE is being performed in a rather low percentage of cases in various countries. For example, Australian surgeons perform early LCHE in $55 \%$ cases, Japanese surgeons in $42 \%$ and in Great Britain it is performed in $11 \%$ of patients ( 9 , 13). Therefore, we can say that the treatment management of acute cholecystitis depends on the preferences of a respective doctor.

In today's era of laparoscopic surgery, the prevailing opinion is that cholecystectomy carried out at the beginning of acute inflammation is technically easier to perform. In an early stage of the disease, the inflammatory edema is limited to the gallbladder area and its wall is still relatively firm. On the contrary, in case of a delayed cholecystectomy we often perioperationally discover firm and vascularized adhesions with surrounding organs and omentum $(2,10)$. This fact is supported by our discovery of an increased average duration of the operation from 75.9 minutes to $90 \mathrm{mi}-$ nutes in a delayed cholecystectomy. In our sample, the conversion rate to a laparotomy was $3.2 \%$ in early operated patients, while in patients who underwent a delayed cholecystectomy it was $16.1 \%$ (Fig. 2). Meta-analyses of different studies, however, do not state a significant difference in conversion rates.

Another advantage of LCHE is an improved post-operation course, which is determined by less burdensome intervention, shorter post-operation recovery and reduction of wound size. This is supported by comparison of the total duration of hospitalization in both examined samples. Last but not least, the social and economic aspects of two hospitalizations needed in a case of a delayed cholecystectomy should be taken into account. The comparison of studied parameters in both groups are listed in Table 1.

The advantage of early LCHE in polymorbid patients over 65 years of age with a severe form of cholecystitis is a swift removal of the infectious focus from the organism. This ensures lower stress for the patient along with a better recovery.

\section{Conclusion}

In conclusion, the lack of consensus regarding the timing of cholecystectomy for acute cholecystitis remains the biggest issue. There is an ongoing worldwide discussion about the modern concept of cholecystectomy being performed within 24 hours since the admission to hospital, i.e. immediate laparoscopic cholecystec- 
tomy. Despite the size of our sample, according to the preliminary results, we consider this concept to be most appropriate. Therefore, we believe this model will become a method of choice for patients with acute cholecystitis hospitalized at surgical clinics.

\section{References}

1. Frič P, Ryska M. Digestivní endoskopie a laparoskopická chirurgie. Praha: Grada Publishing, 1995: 125-135.

2. Cameron IC, Chadwick C, Phillips J, Johnson AG. Acute cholecystitis room for improvement? Ann R Coll Surg Engl 2002; 84: 10-13.

3. Csikesz N, Ricciardi R, Tseng JF et al. Current status of surgical management of acute cholecystitis in the United States. World J Surg 2008; 32 (10): 2230-2236.

4. Gutt CN. Akute Cholezystitis: primär konservatives oder operatives Vorgehen? Der Chirurg 2013; 84: 185-190.

5. Koo KP, Thirlby RC. Laparoscopic cholecystectomy in acute cholecystitis: What is the optimal time for operation? Arch Surg 1996; 131: 540-544.

6. Ohta M, Iwashita Y, Yada K. Operative timing of laparoscopic cholecystectomy for acute cholecystitis in a Japanese institute. JSLS 2012; 16 (1): 65-70.

7. Low JK, Barrow P, Owera A et al. Timing of laparoscopic cholecystectomy for acute cholecystitis: evidence to support early interval surgery. Am Surg 2007; 73 (11): 1188-1192.
8. Hirota M, Takada T, Kawarada Y. Diagnostic criteria and severity assessment of acute cholecystitis: Tokyo Guidelines. Hepatobiliary Pancreat Surg 2007; 14: 78-82.

9. Lujan JA, Parrilla P, Robles R, Marin P, Torralba JA, GarciaAyllon J. Laparoscopic Cholecystectomy Vs Open Cholecystectomy in the treatment of acute cholecystitis: a prospective study. Arch Surg 1998; 133: 173-175.

10. Hartwig W, Büchler MV. Akute Cholezystitis. Der Chirurg 2013; 84: $177-178$.

11. Strasberg MS. Acute calculous cholecystitis. N Engl J Med 2008; 358: 2804-2811.

12. Koo KP, Thirlby RC. Laparoscopic cholecystectomy in acute cholecystitis: What is the optimal time for operation? Arch Surg 1996; 131: 540-544.

13. http://emedicine.medscape.com.

14. http://www.ncbi.nlm.nih.gov/pmc/articles/PMC1805989/?page=1.

15. http://apps.who.int/classifications/icd10/.

16. Campanile et al. Acute cholecystitis: WSES position statement. World J Emerg Surg 2014; 9: 58.

17. Gutt CN et al. Acute cholecystitis: Early versus delayed cholecystectomy, A multicenter randomized trial. Ann Surg 2013; 258 (3).

Received September 17, 2015. Accepted September 25, 2015. 